Praxis. ReVista de Filosofía № 73

ENERO - JUNIO 2016

http://dx.doi.org/10.15359/praxis.73.2

ISSN: 1409-309X

\title{
LAS CATEGORÍAS DE LO ABSTRACTO Y LO CONCRETO
}

\section{THE CATEORIES OF “THE ABSTRACT” AND “THE CONCRETE”}

Roy Alfaro Vargas

Universidad Nacional de Costa Rica

Recibido: 25 de marzo, 2015 / Aceptado: 22 de junio, 2015

Resumen: Este artículo aborda la discusión sobre las categorías de lo abstracto y lo concreto en el ámbito del método dialéctico. El análisis se realiza dentro del actual contexto de la crisis capitalista y el nuevo auge del marxismo, enfocándose principalmente sobre algunos autores anglosajones (Lebowitz, Roper y Banaji), los cuales han aplicado estas categorías a diferentes objetos de estudio, mas en una forma totalmente alejada de las verdaderas dimensiones que tales categorías tenían para Marx. Finalmente, se definen estas categorías buscando claridad y consistencia en su aplicación.

Palabras clave: Marx, método dialéctico, historia, ciencia, historicismo

Summary: This article deals with the discussion on the categories of the abstract and the concrete, within the confines of the dialectical method. The analysis is performed into the context of the current capitalist crisis and the new boom of Marxism, focusing fundamentally on some Anglo-Saxon authors (Lebowitz, Roper, and Banaji) who apply these categories to different subjects, but in a way totally disconnected from the true dimensions that these categories had for Marx. Finally, these categories are defined looking for clarity and consistence in its application.

Keywords: Marx, dialectical method, history, science, historicism.

La caída del socialismo en la Unión Soviética y Europa del Este llevó a muchos a pretender que la crítica del capitalismo de Marx era irrelevante (Selwyn, 2013). Así, entre 1991 y 2008, el neoliberalismo relegó «a Marx al cesto de la basura de la historia» ${ }^{1}$ (Breckman, 2013, p. 1).

1 Esta y las siguientes traducciones de textos citados del inglés y el alemán son mías. 
Mas, en el 2008 y con el estallido de la crisis financiera, se evidenció que tal crisis era «solo un síntoma de un proceso más distendido en el tiempo (...) un síntoma más del agravamiento de una crisis sistémica» (Alfaro, 2011a, pp. 290-291); luego, el marxismo volvía a tomar su lugar en la crítica social, es decir, «la crítica de la economía política está recuperando su lugar central en la teoría y la práctica» (Fraser, 2013, p. 5). Lo que el neoliberalismo separó (la economía de la política), conformando a la vez un mundo de luchas identitarias autistas y, en algunos casos, sin sentido, o sea, la nomocracia posmoderna, 2 se ha desquebrajado en mil pedazos bajo el peso de las contradicciones de la sociedad consumista de consumo restringido. ${ }^{3}$

Esta crisis del capitalismo ha alterado todo el panorama político-económico. En este marco, se extiende «el poder del Estado chino a lo largo del mundo» (Sanderson y Forsythe, 2013, p. xviii); el posmodernismo deviene en una abierta posición de ultraderecha, post-postmodernismo, entendido como la puesta en práctica de la lógica del capital financiero, la lógica de la intensidad, dentro de la producción cultural (Nealon, 2012); ${ }^{4}$ Wal-Mart patrocina a Walton Scholars en un programa que lleva a sus aulas a personas de todas las Américas, con el fin de inocularles «el evangelio de Wal-Mart a sus naciones y comunidades» (Apple, 2013, p. 135). Mientras esto sucede, la derecha académica trata de presentar al marxismo (otrora fallecido, según la misma derecha) como un elemento donde «el postindustrialismo, el posmodernismo, la sociedad de la información, el triunfo del neoliberalismo, la globalización misma; todos reforzaron la idea que el capitalismo se ha movido más allá de la estructura marxiana» (Breckman, 2013, p. 273), por lo que se derivaría de las palabras de este autor que el marxismo sería hoy inservible. ${ }^{5}$

Asimismo, la derecha académica latinoamericana se ha dado a la tarea de desprestigiar o tergiversar también al marxismo: Espinoza (2011) puso al marxismo a la altura de la religión; Güendel (2011) ligó, desde una perspectiva culturalista, a Marx con una posición eurocentrada que no le permitió ver el rol de América Latina en el contexto capitalista; Llanos Villajuán (2011)

2 Para profundizar en el concepto de nomocracia posmoderna, véase Alfaro (2012).

3 Este concepto se ha acuñado en: Alfaro (2011b).

4 En español, al respecto se puede consultar Alfaro (2014a).

5 Warren Breckman (2013), apuntó a un giro simbólico como una forma de enfrentar la actual crisis, con lo cual su post-marxismo (que es en realidad un antimarxismo) se conecta con el post-postmodernismo de Nealon (2012). 
redujo el marxismo a una ciencia empírica plagada de fallos y deficiencias; ${ }^{6}$ sin olvidar la propuesta post-marxista (abiertamente antimarxista) de Fair (2010a y 2010b) o el marxismo analítico de Perissinotto (2010). Por su parte, García Quesada definió muy pintorescamente el marxismo (con un importante sesgo posmoderno, dentro de su antimarxismo petit-bourgeois) como un pensamiento que «se caracteriza ante todo por el imperativo de totalizar historizando» (2007-2009, p. 68). ${ }^{7}$

Así, el sesgo antimarxista que se ha producido después del 2008, ${ }^{8}$ expresa como su correlato el fracaso de las metodologías fenomenológicas. Los estudios culturales y de la subalternidad se enfrascan en su propia anulación (en el contexto de la crisis actual, donde algunos Estados roban el dinero a los ahorrantes para entregárselo al gran capital), ya que estos estudios «no pueden ser una teoría del capitalismo globalizante ni su crítica, ya que sistemáticamente deforman cómo el capitalismo funciona» (Chibber, 2013, p. 286) y, por ende, «si una teoría [los estudios culturales y de subalternidad] no puede básicamente comprender cómo trabaja el capitalismo, entonces la idea de suplantar los radicales análisis marxistas o de otro tipo no pueden ser tomados seriamente» (2013, p. 288). En consecuencia, hoy el marxismo ha dejado de ser el pretendido relicto fósil de los posmodernos, y se ha convertido en el bisturí que disecciona el putrefacto cadáver del último capitalismo y de su aberrante hijo, el neoliberalismo, el cual ha mutado en algo irreconociblemente corrupto, el neoliberalismo intervencionista.

No obstante, el resurgir del marxismo viene acompañado de visiones que lo deforman, lo invierten, y que repiten los errores del pasado. Pensadores del Primer Mundo han hecho propuestas donde el método dialéctico se corrompe hasta analogarse a los paradigmas positivos (positivismo y fenomenología). ¿Se hace esto con intención? No lo sé. Lo que sí alcanzo a vislumbrar es que si el marxismo y la necesidad de una transformación social

6 El lector puede hallar una crítica más exhaustiva a Llanos, en: Alfaro (2013a).

7 El caso de García es interesante, por cuanto el autor se ha presentado en algunos contextos como un autor marxista -por ejemplo, en García (2013), con un texto plagado de inconsistencias y omisiones-, pero su definición del método dialéctico y una tendencia identitarista lo acercan más al pensamiento de Llanos (2011) que al de Marx, el cual el lector podrá constatar por sí mismo más adelante. Asimismo, García olvidó que Lefebvre señaló que «lo económico sigue siendo esencial, aunque ha sido puesto en tela de juicio como tal, en su prioridad» (Lefebvre, 1983, p. 273).

8 Durante el período de dominio neoliberal más bien Marx ha sido instrumentalizado por el postestructuralismo, donde «cada pensador ha escrito y usado a Marx en muchos sentidos» (Choat, 2010, p. 1), es decir, «un Marx separado del humanismo, del historicismo y de Hegel» (p. 28). 
tienen validez, esta radica en una reflexión derivada de las condiciones de pobreza, exclusión, violencia, explotación (nacional y transnacional) que experimentamos los latinoamericanos, los asiáticos y los africanos. ${ }^{9}$ Dicho de otra manera, no podemos esperar nada de los intelectuales anglosajones y europeos, ellos tienen que proteger su nivel de vida, que es muy alto. ${ }^{10}$

Dentro de este marco, en la filosofía continental europea y la anglosajona se dan una serie de manifestaciones que abrazan el nombre de Marx y del marxismo, las cuales se caracterizan, ante todo, por un rompimiento de la unidad dialéctica de lo abstracto y lo concreto.

Tenemos, entonces, y sin pretender agotar aquí la dinámica de estos movimientos, un nuevo historicismo representado por Lebowitz (2009, 2010 y 2012), Banaji (2010) y Roper (2013). Empuja asimismo fuerte y amparado en figuras de gran peso comercial, el comunismo lacaniano, con Dean (2012), Bosteels (2011), Badiou (2012) y Žižek (2012a y 2012b). ${ }^{11}$ De igual modo, los estudios culturales marxistas se lanzan al análisis de la Web 2.0 (especialmente en la revista tripleC) y con una fuerte presencia de la teoría de la auto-organización, con autores como Fuchs (2014a, 2014b, 2014c), Mosco (2014), etc. Finalmente, está el grupo ligado a la noción de la política de la abstracción, ${ }^{12}$ con autores como Paolucci (2011), Krinsky (2013), Harvey (2014), Smith (2014), Moseley (2014), Fineschi (2014) y Reuten (2014). Todo esto sin entrar aquí a establecer los lazos existentes entre estos diferentes movimientos, tanto a través de la política de la abstracción misma como mediante la teoría de conjuntos y la noción de conjunto vacío, que parece subyacer a casi todos los movimientos mencionados.

Es en este contexto que se abordará el análisis de las categorías de lo abstracto y lo concreto, fundamentalmente alrededor de las propuestas de Lebowitz (2009, 2010 y 2012), Roper (2013) y Banaji (2010).

9 Recordemos que Marx (1977) hablaba del imperativo de partir de la necesidad sensorial.

10 Hay áreas donde los salarios rondaban, en datos del 2006, entre un mínimo de $\$ 180.000$ y un máximo de $\$ 277.700$ anuales (Stephan, 2012)

11 El lector puede profundizar en: Alfaro (2014b).

12 En español, para insertarse en la cuestión de la política de la abstracción, se puede consultar Alfaro (2013b), donde el lector puede familiarizarse inicialmente con esta temática, pero que la propuesta aquí desarrollada profundiza con los aportes de Harvey (2014), Callinicos (2014), etc. 


\section{Lo abstracto y lo concreto según el mundo anglosajón}

Lebowitz tenía claro teóricamente que «la metodología (...) es lo que sobre todo distingue al marxismo de "la ciencia social burguesa"» (2009, p. 247)..$^{13}$ De igual modo, Lebowitz comprendía que lo concreto es el punto de partida de toda investigación efectuada con el método dialéctico:

Iniciando por el estudio de lo concreto, es posible destilar principios simples que permitan deducir elementos en una secuencia determinada por la naturaleza de sus relaciones dentro de la sociedad en cuestión. La deducción permite comprender las interconexiones dentro del todo concreto y así no tratar los elementos como «vecinos autónomos independientes». Proceder de estas simples concepciones a una concepción del todo "como una rica totalidad de muchas determinaciones y relaciones» fue como Marx construyó el concepto de sistema orgánico. A través de este método, él fue capaz de demostrar cómo los últimos desarrollos lógicos en el capitalismo están latentes en los conceptos.

Pero el punto de inicio debe ser esa apropiación de lo concreto en detalle (2012, p. 34).

A pesar de esta supuesta claridad teórica de Lebowitz, esto no le impidió cometer un grave error en la aplicación del método, cuando definió el objeto de estudio en su libro The Contradictions of "Real Socialism", es decir: «Iniciar por lo concreto: las características de la Unión Soviética y de los países del Este de Europa, siguiendo el modelo soviético desde aproximadamente los años 1950 hasta los años 1980» (Lebowitz, 2012, p. 36).

El problema con este concreto lebowitziano es que no es tal. Hace dos décadas la Unión Soviética y los países comunistas del este ya no existían o las condiciones eran completamente otras. Lo que Lebowitz tenía era un conjunto de datos que tenían algún interés historiográfico (en su sentido más positivista), pero lo cierto es que la crisis actual del capitalismo nos plantea problemas teórico-prácticos que es preciso enfrentar hoy; por ejemplo, la necesidad de articular movimientos de transformación social (a escala nacional, pero que permitan la interacción con movimientos en Estados Unidos

13 «La revolución introducida por Marx fue en la metodología» (Levine, 2012, p. 313). 
y Europa, con el fin de ayudar al colapso de tales bloques capitalistas) con base en la experiencia vivida en varias partes del mundo (aunque no todas publicitadas por la prensa burguesa), con el objetivo de alejar tales movimientos de los imperativos de la pequeña burguesía burocrática (entendidas aquí las burocracias estatales, las nacionales privadas y las transnacionales). Esto debido a que esta clase media burocrática manipula los movimientos hacia la necesidad propia de no perder su nivel de vida; luego, como en la Primavera Árabe, las clases bajas han puesto los muertos y la clase media, la pequeña burguesía, se ha apropiado del poder para no cambiar nada y menos todavía amarrarse a alguna acción cualitativamente revolucionaria.

Lebowitz no partió de lo concreto, sino de un historicismo con tintes metafísicos e idealistas, elementos que son más evidentes en su texto The Socialist Alternative (2010). En tal propuesta Lebowitz aboga por una buena sociedad que permita «el completo desarrollo del potencial humano. Este es realmente el punto de partida - como lo fue para Marx y otros socialistas decimonónicos» (2010, p. 13).

Así, el punto de inicio para Lebowitz no es lo concreto, sino una idea del siglo XIX, o sea, algo abstraído; ${ }^{14}$ lo cual, según este autor, «hoy puede ser claramente visto en la Constitución Bolivariana de Venezuela» (Lebowitz, 2010, p. 14). Lebowitz, por consiguiente, inició con una idea abstraída y llegó a justificarla por otra abstracción, la Constitución Bolivariana, que en tanto discurso jurídico no es concreto. Una constitución política no es ni supera la realidad concreta. De este modo, Lebowitz, por sus simpatías con el proyecto venezolano, olvidó que no es «posible llevar a cabo el socialismo en un único país» (Eagleton, 2011, p. 16). Extrañamente, Lebowitz cometió los mismos errores de Lenin, pero, a diferencia de Lenin, Lebowitz ya sabía lo que podría pasar.

Lo concreto lebowitziano no es más que un discurso abstraído y, por tanto, desconectado de lo concreto, lo cual imposibilita una praxis política acertada, al dejar la acción política sin objeto de transformación, solo permanece el discurso. De este modo, Lebowitz, al igual que Callinicos, borró toda diferencia entre lo abstracto y lo concreto: «La distinción entre lo abstracto y lo concreto (...) es una entre conceptos» (2014, p. 131). En

14 Uso abstraído para diferenciarlo de lo abstracto, implicando este último una relación estrecha y dialéctica con lo concreto, mientras lo abstraído presupone una separación con respecto a lo concreto. 
otras palabras, «lo abstracto y lo concreto son un asunto de los lugares que los conceptos ocupan en el discurso» (Callinicos, 2014, p. 132). Como por arte de magia, todo se ha reducido con esta propuesta a lenguaje, el cual se cataloga como más abstracto o más concreto en función de una estructura sintáctica determinada y con lo cual, según Callinicos, se trasciende «la distinción entre texto y contexto» $(2014$, p. 23$)$, ya que esencialmente ambos, para él, son discurso.

Por otra parte, Banaji (2010), en Theory as History, se queja de la «mala teoría». Por mala teoría Banaji comprende «la sustitución de explicaciones puramente teóricas por la investigación histórica y/o recurrir a una teoría que es ella misma simplemente una sarta de abstracciones» (2010, pp. 7-8). Si Banaji arremetió contra la teoría por ser una sarta de abstracciones, entonces lo opuesto a la abstracción, dentro del paradigma dialéctico, sería lo concreto; así Banaji abogó, como Lebowitz, por asirse a lo concreto.

Sin embargo, el desarrollo del texto de Banaji nos lleva a afrontar los mismos inconvenientes que la propuesta de Lebowitz, ya que el conjunto de ensayos que comprenden el texto banajiano pretende

Primeramente trazar una concepción general de los modos de producción como caracterizaciones históricas de épocas completas, en otras palabras, restituir el sentido de la complejidad histórica a ellos y luego ilustrar/explorar algo de esta complejidad en estudios detallados, basados en cuanto sea posible en material de fuentes primarias (Banaji, 2010, p. 1).

Todo esto es realizado «a través de un proceso de producir conceptos en el mismo nivel de "concretez" histórica» (Banaji, 2010, pp. 47-48).

Las objeciones hechas a Lebowitz también recaen sobre Banaji. Como el mismo Banaji indicó, él quería basarse «en material de fuentes primarias» (2010, p. 1), es decir textos, porque los modos de producción no-capitalistas ya no existen; luego a lo que él tuvo acceso no fue a cada modo de producción, y aunque el discurso histórico no sea precisamente teoría, sí es en tanto discurso una abstracción. Lo de Banaji es un historicismo con un sesgo evolucionista, haciéndose pasar por el producto de una posición anclada en lo material, lo concreto, cuando en realidad es nuevamente puro 
idealismo. Al igual que en Lebowitz, el conflicto con el carácter práctico de lo concreto lo sume en lo abstraído.

Roper (2013), en The History of Democracy, nos remite a la idea de «que la realidad social está siempre en un constante estado de flujo y que toda forma de democracia existe solo en el movimiento fluido» (pp. 2-3), desarrollado esto dentro de «las características fundamentales del método de Marx, particularmente con respecto a su relación con el método de $\mathrm{He}$ gel, [donde] pocos negarían que el proceso de abstracción es absolutamente central para este» (Roper, 2013, p. 3).

Así, Roper también cayó en la cuestión de la abstracción, tanto como lo vimos anteriormente en Banaji y Lebowitz, al grado que es imposible discernir si lo que Roper creyó que se movía era la realidad o la abstracción por él creada. Mirando más de cerca el desarrollo del texto de Roper, es innegable que aquello que se mueve es la abstracción, el dato, la estructura lógica, con lo cual Roper se cernió sobre el explicar «la historia de la democracia (...) para identificar, imaginar y clarificar alternativas de potencial democrático en un mundo dominado por el capitalismo neoliberal y los Estados Unidos» (2013, p. 2).

Dicho de otra manera, Roper trató de «identificar, imaginar y clarificar» (2013, p. 2) un concepto de democracia (definido por él mismo mediante su énfasis en la abstracción) que sea aplicable a la situación actual, con lo cual se crea una relación no-dialéctica, mecánica, que va de lo abstraído a lo concreto, y donde este último solo sería manifestación de tal abstracción. En otras palabras, lo abstraído roperiano conformaría lo concreto. Roper buscó establecer algún tipo de ley para aplicarla a la realidad actual. El historicismo de Roper lo acerca más al sistema de Hegel que al método de este. ${ }^{15}$

Es patente que Lebowitz, Banaji y Roper mezclaron la terminología del método dialéctico con una implementación positiva (o positivista) del análisis histórico, con lo cual lo concreto se funde y desaparece en su política de las abstracciones, el dato se asume como lo real (muy al estilo de la filosofía anglosajona) y la historia se presenta con un énfasis en el pasado. Con este énfasis se moraliza la historia y la historiografía, al ser el presente el simple

15 Recordemos que «Marx dividió la filosofía especulativa hegeliana en dos partes, sistema y método. Él rechazó los aspectos sistémicos de la filosofía especulativa hegeliana, pero continuó los aspectos metodológicos» (Levine, 2012, p. 305). 
receptáculo de las «enseñanzas» del pasado, pero desatendiendo el presente mismo, en tanto que es lo concreto nulificado por sus posiciones abstraídas.

Dentro de esta perspectiva, la noción histórica de Banaji, Roper y Lebowitz no se diferencia, en lo esencial, de la historiografía de derecha. Por ejemplo, si tomamos el texto de Molina Jiménez (2012), titulado Revolucionar el pasado, nos encontramos con los mismos problemas que con los autores arriba analizados. El texto de Molina muestra un paupérrimo manejo teórico, fundamentándose en la idea de un proceso histórico dentro de la historiografía costarricense marcado por un desarrollo mecánico, que desemboca (amparado en una concepción metafísico-posmoderna de la noción de lo particular) en el paradigma, para él, insuperable, absoluto y substancializante de la Nueva Historia (New Cultural History o New Narrative History, en el contexto anglosajón), asumida como el happy end del desarrollo de la historiografía, y presentando como novedad esa vieja y obsoleta metodología fenomenológica ( $y$, por ende, positiva) que niega lo concreto al sumirse en una visión romántica del pasado, perdiendo, en consecuencia, todo valor práctico. Si se quisiera encontrar algún valor en el texto de Molina, este solo sería el distorsionar, invertir, la realidad en un momento crucial para los intereses de la derecha neoliberal, que ve agonizar el capitalismo. ${ }^{16}$

De igual manera, Lebowitz, Banaji y Roper presentaron una serie de propuestas que no se alejan del texto de Molina, al destrozar la relación entre lo abstracto y lo concreto, que es fundamental en la dialéctica marxiana y marxista.

\section{Lo abstracto y lo concreto en (el) marx(ismo)}

Para traerse abajo los planteamientos de Banaji, Roper y Lebowitz, Marx señaló que:

El método de elevarse de lo abstracto a lo concreto es el único modo, para el pensamiento, de apropiarse de lo concreto, para reproducirlo como un

16 Como apuntó Bruno: «La ciencia burguesa es la sociedad burguesa porque contribuye al reforzamiento y conservación de esta. Y esta es la determinación práctica del saber burgués. Pero la cuestión estriba en que a pesar del carácter apologético y conservador de la que podríamos llamar ideología-ciencia burguesa, la sociedad burguesa en un determinado momento histórico comienza a ser cuestionada por las contradicciones sistémicas que desarrolla en su seno, manifestando así su tendencia al agotamiento como forma de reproducción social» (2011, p. 84). 
concreto mental. De ningún modo, no obstante, el proceso de origen de lo concreto mismo (1983, p. 35).

Más claramente, las abstracciones no producen lo concreto; la buena sociedad de Lebowitz, la democracia de Roper y la secuencia de modos de producción de Banaji no son algo concreto, no son la fuente de realidad concreta alguna, sino, como ya se apuntó, son lo abstraído en tanto desconectado de lo real concreto. Lo concreto para Marx y Engels implica que «la historia cesa de ser una colección de hechos muertos [datos], como lo es para los empiristas o una actividad imaginada de sujetos imaginados, como con los idealistas» (1976, p. 43). Lo concreto no puede supeditarse a una lógica donde «los conceptos más abstractos y más iniciales sirven para explicar los más tardíos y más concretos» (Callinicos, 2014, p. 130), en un proceso, por ende, de abstracción dosificada que le permite, desde tal perspectiva, a

Marx constantemente integrar más material empírico dentro de su análisis (...) Sin embargo, la incorporación de material empírico dentro de determinaciones específicas debe ser vista primeramente como el modo en el cual Marx agrega contenido fresco a su análisis. Esto no representa ninguna clase de corroboración empírica directa de proposiciones individuales (Callinicos, 2014, p. 153).

Es decir, dentro de esta lógica que destruye la relación dialéctica entre lo abstracto y lo concreto, se usa «el poder de la abstracción para construir un modelo de cómo funciona la locomotora económica del capitalismo» (Harvey, 2014, p. 8), «identificando las relaciones claves y comprendiendo la relación de las partes con los todos» (Krinsky, 2013, p. 108), dentro de la idea de que «los conceptos de totalidad y de relación parte-todo son centrales en la propuesta de conceptualización de Marx» (Paolucci, 2011, p. 57). Dicho de otra manera, se crea un modelo donde diferentes subconjuntos conforman el conjunto capital y en donde las llamadas conexiones internas permiten crear "parcialidades analizables del conjunto inicial y definidas por su carácter empírico» (Alfaro, 2013, p. 207), o sea, se remite a «una totalidad cuantificable y, por ende, positiva» (p. 207), a través de «los elementos más abstractos de los niveles más concretos de la abstracción» (Fineschi, 2014, p. 162). 
Esta perspectiva «abstraccionista» olvida que el método dialéctico, entonces, como ciencia debe acatar la siguiente condición:

La percepción sensorial (...) debe ser la base de toda ciencia. Solamente cuando ella procede desde la percepción sensorial en la doble forma de consciencia sensual y de necesidad sensorial —es decir, solo cuando la ciencia procede desde la naturaleza- es verdadera ciencia (Marx, 1977, p. 105).

Volvamos a Lebowitz para observar las sutilezas de la última afirmación de Marx tomada de los Manuscritos de 1844. Cuando Lebowitz planteaba como objeto de su investigación «las características de la Unión Soviética y de los países del Este de Europa (...) desde aproximadamente los años 1950 hasta los años 1980» (2012, p. 36), este autor confundía el discurso (los posibles diferentes tipos de fuentes: textos, documentales, etc.) con la realidad del bloque soviético. El problema es que para la fecha de publicación del texto de Lebowitz, The Contradictions of "Real Socialism", el mundo soviético tenía aproximadamente dos décadas de haber desaparecido; luego, es irreal, por ende es como hecho muerto, algo abstraído, desligado de lo concreto real.

Hubiese sido diferente si el objeto de estudio de Lebowitz hubiera sido el discurso sobre las características de la Unión Soviética y los países de Europa Oriental entre 1950 y 1980, y en relación con quizás el discurso actual sobre el marxismo, ya que el discurso como documento y dentro de una investigación más amplia sería completamente válido. ${ }^{17}$ En otras palabras, cuando Marx señala «el método de elevarse de lo abstracto a lo concreto» (1983, p. 35) lo que nos indica es que lo importante no es «derivar lo general de lo particular al estilo de los empiristas» (Eagleton, 2012, p. 8), sino que lo concreto, que siempre es particular, se aborda desde una perspectiva conceptual determinada que es confrontada con el hecho vivo, sensorial, y que ante este existe (en cuanto es lo abstracto, que es luego lo lógico, o sea, es discurso) entre lo concreto real y lo concreto espiritual una identidad, que hace a lo abstracto (el discurso, el concepto) aplicable a tal particular concreto real, pero también hay una diferencia, ya que «lo concreto es concreto, porque es la síntesis de muchas determinaciones, por ende unidad de lo múltiple»

17 Lógicamente, apuntando a las ciencias del lenguaje que han sido parte del desarrollo histórico de la división social del trabajo. 
(Marx, 1983, p. 35), y en cuanto múltiple (por ende, diferente y entrópico) el concepto no corresponde a la identidad lógico-aristotélica $(A=A$, la cual implica un solo particular existente), sino que es una congruencia $(A \equiv A$, que implica dos particulares que se diferencian en su movimiento, que son tanto identidad como negatividad $\left.{ }^{18}\right)$; por lo que el discurso científico debe estar constantemente actualizándose para comprender esa concretez (calidad de lo concreto) que es entrópica, que se mueve por ese desfase que la negatividad introduce en la identidad, que asume lo concreto «en el conjunto de su movimiento» (Lefebvre, 2013, p. 89).

Esto que vengo de expresar conlleva que hay, dentro de la perspectiva del método dialéctico, a través de la superación dialéctica (Aufhebung), la obligación de teorizar. Es decir, si me acerco a lo concreto real y lo hago mediante un discurso (lo abstracto), ya más o menos elaborado que es congruente con tal objeto; entonces, después de la confrontación de estos es preciso reelaborar lo abstracto para que se solvente el desfase que yacía en el discurso inicial, desfase que existía como diferencia, bajo pena de pretender «deducir lo particular de lo general a la manera de los racionalistas» (Eagleton, 2012, p. 8). En otras palabras, el proceso de investigación rehace/ reencuentra «el todo, lo concreto, pero esta vez analizado y comprendido» (Lefebvre, 2013, p. 92).

Entonces, estas categorías de lo abstracto y lo concreto deben comprenderse en función de aquellas de lo lógico y lo histórico, debido a que estas dos últimas categorías introducen la relación entre el tiempo y el pensamiento, permitiendo el movimiento de lo concreto real a lo concreto espiritual (lo abstracto) y así sucesivamente: abstracto-concreto-abstracto-concreto. ${ }^{19}$

El problema de Lebowitz, Banaji y Roper es que desconectaron lo abstracto (que reaparece en la relación lógico-histórica como lo lógico) del proceso histórico, con lo que lo concreto espiritual adquiere un valor axiomático que sobrepone la estructura discursiva rígida a la movilidad de lo real concreto, en tanto proceso de deducción. Lo abstracto en cuanto manifestación lógico-categorial depende, en términos dialécticos, de lo histórico, o sea, del tiempo, de la entropía y de hecho del ser social, del ser de la especie

18 La idea de congruencia la puede hallar el lector en: Kojève (2013).

19 «Pensamiento y ser son así ciertamente distintos, pero al mismo tiempo están en unidad uno con otro» (Marx, 1977, p. 100). 
(Gattungswesen) que solo se constituye en «la historia [que] no es nada sino la sucesión de generaciones separadas» (Marx y Engels, 1976, p. 58).

Abordar lo abstracto como expresión de lo lógico, que solo adquiere sentido por lo histórico, es comprender «el establecimiento del verdadero materialismo y de la ciencia real, haciendo de la relación del "hombre con el hombre” el principio básico de la teoría» (Marx, 1977, p. 135), por cuanto lo concreto no es un en sí algo dado de una vez por todas como elemento natural, sino que lo concreto real es real porque hay un concreto espiritual (lo abstracto) y, en consecuencia, en cuanto lo concreto real es un concreto para sí, o sea, un concreto real que históricamente es parte de un proyecto social en tanto expresión del ser social: de ahí la unidad y lucha de contrarios de lo abstracto y lo concreto.

Además, y esto es crucial en la unidad dialéctica de lo abstracto y lo concreto, estas categorías permiten la interacción dialéctica de sujeto y objeto, en tanto el sujeto a través del pensamiento (lo lógico y lo abstracto como mediaciones) solo puede constituirse activamente en función de los imperativos derivados del objeto (lo concreto, lo histórico), evitando que el sujeto devenga un sujeto trascendental o, al revés, que el objeto no se constituya en sí como un substancializante que haría del sujeto un simple recipiente. O sea, más bien el objeto es confrontado por un sujeto activo que hace al objeto finalmente parte de un proyecto, de un para sí. En otras palabras, la relación de lo concreto y lo abstracto evita, dentro del método dialéctico, el idealismo y la metafísica (algo que al final Lebowitz, Banaji y Roper no lograron evadir).

\section{A manera de conclusión}

Así como no todo lo que brilla es oro, no todos los que se sirven de la terminología marxista son marxistas.

Dentro de la lógica de circulación-reproducción del capital y aún más en época de crisis, todo deviene mercancía y, por eso, no es de extrañar que las grandes editoriales transnacionales publiquen textos de una postura, la marxista, que debe conllevar la superación del capitalismo, por tanto la destrucción del circuito de circulación-reproducción del capital mismo. Ya este hecho debe ponernos a nosotros, el todavía olvidado y explotado Tercer 
Mundo, sobre aviso, para no aceptar de buenas a primeras lo que viene de Europa y Estados Unidos. Es muy común en los académicos latinoamericanos una falta de autoestima generalizada y una carencia de toda autovaloración de su trabajo intelectual, que los lleva a asumir irreflexivamente teorías o pseudoteorías como si fueran un regalo de los dioses del Primer Mundo.

Hoy, nosotros, marxistas latinoamericanos, debemos inexorablemente romper con esta tónica y comenzar a elaborar el proceso lógico (lo abstracto) requerido para la comprensión y transformación de nuestra realidad concreta, sin olvidar que el proceso de fondo, como totalidad que es, no solo cognoscitivo, gnoseológico, sino también político, ${ }^{20}$ es un para sí. Precisa tomar mayor consciencia de la subordinación mental que, como intelectuales o académicos del Tercer Mundo, experimentamos, se quiera o no, con respecto a Europa y, por derivación, a Estados Unidos, y entender que aquellos no son mejores que nosotros. En el mejor de los casos, es claro, lo que tienen a su favor son más recursos económicos (saqueados históricamente a nuestros países) y que también los benefician los procesos de legitimación.

Con respecto a lo abstracto y lo concreto, es innegable que lo concreto real debe fundamentar los procesos de investigación dentro del método dialéctico. Lo concreto se caracteriza, entonces, por ser un particular que se aprehende inicialmente de manera senso-perceptualmente, luego lo concreto se ubica en tiempo presente (en el aquí y el ahora) y, finalmente, tiene un carácter práctico. ${ }^{21}$ Olvidar esto lleva a plantear lo abstraído en lugar de lo abstracto, categoría esta última que solo adquiere validez a través de lo histórico, como ya vimos. Finalmente, lo abstracto es entonces el discurso sobre lo concreto.

Lo que hace al marxismo diferente de las ciencias positivas (fenomenológicas o positivistas) es el método, por eso, a pesar de que «la dialéctica es muy difícil de comprender» (Paolucci, 2001, p. 30), es imperativo una profunda comprensión de sus fundamentos, su funcionamiento y su relación

20 Fundamental en esto es desligarse del vulgar academicismo que acompaña, en muchas revistas y academias latinoamericanas, el proceso de investigación-publicación. El tener que presentar los datos totalmente vaciados de juicios políticos es una de las más nefastas formas de control socio-intelectual que se tienden a reproducir en Latinoamérica. Esto sin olvidar el «titulismo» que se ha desatado, donde se llega a creer que el nivel académico expresado por un título es igual a capacidad intelectual: la forma se confunde con el contenido.

21 «a vida social es esencialmente práctica» (Marx, 1978, p. 535). 
con el método hegeliano (esto último para acceder a las sutilezas que Marx le introdujo).

Asimismo, se justifica aquí aclarar que el método dialéctico no implica, en el campo de la historiografía y otras ciencias, que la investigación positivista (que describe muy bien el Ser) se elimine, sino que, al contrario, esta debe ser superada (aufgehoben) con un método que la reinserta en el movimiento de la realidad y ese método es el método dialéctico.

\section{Referencias}

Alfaro, R. (2011a). Capitalismo zombie. Contribución a la crítica del último capitalismo. Telos. Revista de Estudios Interdisciplinarios en Ciencias Sociales 13(3), 285-296.

Alfaro, R. (2011b). Dialéctica de la ficción y el trabajo. Revista de Filosofía, XLIX (126), 61-67.

Alfaro, R. (2012). Henri Lefebvre y el fin de la nomocracia posmoderna. Revista de Ciencias Sociales, III (137), 105-121.

Alfaro, R. (2013a). Dialéctica marxista. Respuesta a Marino Llanos Villajuán. Revista Reflexiones. 92 (2), 131-140.

Alfaro, R. (2013b). Paul Paolucci y la política de la abstracción. Endoxa: series filosóficas $32,207-227$.

Alfaro, R. (2014a). Post-postmodernismo. Revista Reflexiones, 93 (2), 103-113.

Alfaro, R. (2014b). El nuevo comunismo lacaniano. Revista de Ciencias Sociales, II (144), 211-223. http://dx.doi.org/10.15517/rcs.v0i144.17182

Apple, M. W. (2013). Can Education Change Society? Nueva York y Londres: Routledge.

Badiou, A. (2012). The Rebirth of History. Londres y Nueva York: Verso.

Banaji, J. (2010). Theory as History. Essays on Modes of Production and Exploitation, Leiden-Boston: Brill. http://dx.doi.org/10.1163/ej.9789004183681.i-406

Bosteels, B. (2011). The Actuality of Communism. Londres y Nueva York: Verso.

Breckman, W. (2013). Adventures of the Symbolic. Post-marxism and Radical Democracy. Nueva York: Columbia University Press. http://dx.doi.org/10.7312/ columbia/9780231143943.001.0001

Bruno, D. (2011). La dialéctica histórica de Karl Marx: aproximaciones metodológicas para una teoría del colapso capitalista. Hic Rhodus. Crisis capitalista, polémica y controversias, $1,75-86$.

Callinicos, A. (2014). Deciphering Capital. Marx's Capital and its Destiny. Londres: Bookmarks Publications.

Chibber, V. (2013). Postcolonial Theory and the Specter of Capital. Londres: Verso.

Choat, S. (2010). Marx through Post-Structuralism. Lyotard, Derrida, Foucault, Deleuze. London and New York: Continuum.

Dean, J. (2012). The Communist Horizon. Londres y Nueva York: Verso.

Eagleton, T. (2011). Why Marx Was Right. New Haven \& Londres: Yale University Press. 
Eagleton, T. (2012). The Event of Literature. New Haven and New York: Yale University Press.

Espinosa, J. (2011). Religión, utopismo y realismo político en el Renacimiento. Praxis 66, 101-109.

Fair, H. (2010a). La lucha de palabras es la (actual) lucha de clases. Razón y palabra. Primera Revista Digital en Iberoamérica Especializada en Comunicología 73, 1-8. Recuperado de http://www.redalyc.org/articulo.oa?id=199514908029

Fair, H. (2010b). El debate político entre los enfoques marxistas, posmarxistas y posmodernos. La Lámpara de Diógenes 20-21, 237-260.

Fineschi, R. (2014). On Hegel's Methodological Legacy in Marx. In Fred Moseley and Tony Smith (eds.) Marx's Capital and Hegel's Logic. A Reexamination. Pp. 140-163. Leiden and Boston. Brill. http://dx.doi.org/10.1163/9789004270022_008

Fraser, N. (2013). Fortunes of Feminism: From State-Managed Capitalism to Neoliberal Crisis. Londres y Nueva York: Verso.

Fuchs, C. (2014a). Digital Labour and Karl Marx. Nueva York: Routledge.

Fuchs, Ch. (2014b). Critique of the Political Economy of Informational Capitalism and Social Media. In Christian Fuchs and Marisol Sandoval (eds.). Critique, Social Media and the Information Society. Pp. 51-65. New York and London: Routledge

Fuchs, C. (2014c). Karl Marx y el estudio de los medios y la cultura hoy. Telos. Revista de Estudios Interdisciplinarios en Ciencias Sociales 16(3), 495-535.

García, G. I. (2007-2009). Tiempo, trabajo y capital en Marx y Bourdieu: un metacomentario. Abra 37-38, 59-70.

García, G. I. (2013). ¿Lefebvre o Konstantinov? Respuesta a una 'contrarréplica'. Revista de Ciencias Sociales, I, (139), 103-114.

Güendel, H. (2011). Marx sobre América Latina, revisión crítica de una enunciación eurocentrada. Praxis 67, 91-106.

Harvey, D. (2014). Seventeen Contradictions and the End of Capitalism. Nueva York: Oxford University Press.

Kojève, A. (2013). ¿Qué es la dialéctica? Revista de Ciencias Sociales, I (139), 91-102.

Krinsky, J. (2013). Marxism and the Politics of Possibility: Beyond Academic Boundaries. In Colin Barker, Laurence Cox, John Krinsky and Alf Gunvald Nielsen (eds.). Marxism and Social Movements. Pp. 103-121. Leiden and Boston: Brill. http://dx.doi. org/10.1163/9789004251434_006

Lebowitz, M. A. (2009). Following Marx: Methode, Critique and Crisis. Leiden-Boston: Brill.

Lebowitz, M. A. (2010). The Socialist Alternative. Real Human Development. Nueva York: Monthly Review Press. http://dx.doi.org/10.1163/ej.9789004149427.i-372

Lebowitz, M. A. (2012). The Contradictions of "Real Socialism". The Conductor and the Conducted. Nueva York: Monthly Review Press.

Lefebvre, H. (1983). La presencia y la ausencia. Contribución a la teoría de las representaciones. México: Fondo de Cultura Económica.

Lefebvre, H. (2013). Marxismo y sociología. Revista de Ciencias Sociales IV(142), 87-100.

Levine, N. (2012). Marx's Discourse with Hegel. Hampshire and New York: Palgrave Macmillan. http://dx.doi.org/10.1057/9780230360426

Llanos, M. (2011). Crítica de la dialéctica marxista. Letras 82(117), 151-173. 
Marx, K. y Engels, F. (1976). The German Ideology. Moscú: Progress Publishers.

Marx, K. (1977). Economic and Philosophic Manuscripts of 1844. Moscú: Progress Publishers. Marx, K. (1978). Thesen über Feuerbach. Werke Band 3. Berlin: Dietz.

Marx, K. (1983). Grundrisse der Kritik der politischen Ökonomie. Werke Band 42. Berlín: Dietz.

Molina, I. (2012). Revolucionar el pasado. La historiografía costarricense del siglo XIX al XXI. San José, Costa Rica: EUNED.

Mosco, V. (2014). Marx is Back, but Will Knowledge Workers of the World Unite? On the Critical Study of Labour, Media and Communication Today. In Christian Fuchs and Marisol Sandoval (eds.). Critique, Social Media and the Information Society. Pp. 248-260. New York and London: Routledge.

Moseley, F. (2014). The Universal and the Particulars in Hegel's Logic and Marx's Capital. In Fred Moseley and Tony Smith (eds.). Marx's Capital and Hegel's Logic. A Reexamination. Pp. 115-139. Leiden and Boston: Brill. http://dx.doi. org/10.1163/9789004270022_007

Nealon, J. T. (2012). Post-postmodernism or, The Cultural Logic of Just-in-Time Capitalism. Stanford, CA: Stanford University Press.

Paolucci, P. (2001). Dialectical Methodology, Power EG Capital: Dialectical Methods, Foucault's Encounter with Marxism, and Techniques of Class Domination into the Global Era. Tesis para optar por el grado de Doctor en Filosofía. Universidad de Kentucky (USA).

Paolucci, P. (2011). Marx and the Politics of Abstraction. Leiden y Boston: Brill. http://dx.doi. org/10.1163/ej.9789004201378.i-239

Perissinotto, R. (2010). Marxismo e ciência social. Um balanço crítico do marxismo analítico. Revista Brasileira de Ciências Sociais 25(73), 113-128. http://dx.doi.org/10.1590/ S0102-69092010000200007

Reuten, G. (2014). An Outline of the Systematic-Dialectical Method: Scientific and Political Significance. In Fred Moseley and Tony Smith (eds.). Marx's Capital and Hegel's Logic. A Reexamination. Pp. 243-268. Leiden y Boston: Brill. http://dx.doi. org/10.1163/9789004270022_012

Roper, B. S. (2013). The History of Democracy. A Marxist Interpretation. Londres: Pluto Press Sanderson, H. y Forsythe, M. (2013). China's Superbank. Debt, Oil and Influence - How China Development Bank Is Rewriting the Rules of Finance. Singapore: Bloomberg Press.

Selwyn, B. (2013). Karl Marx, Class Struggle and Labour-Centred Development. Global Labour Journal 4(1), 48-70. Recuperado de http://digitalcommons.mcmaster.ca/ globallabour/vol4/iss1/3. http://dx.doi.org/10.15173/glj.v4i1.1128

Smith, T. (2014). Hegel, Marx and the Comprehension of Capitalism. In Fred Moseley and Tony Smith (eds.). Marx's Capital and Hegel's Logic. A Reexamination. Pp. 17-40. Leiden and Boston: Brill. http://dx.doi.org/10.1163/9789004270022_003

Stephan, P. (2012). How Economics Shapes Science. Cambridge (MA) and London: Harvard University Press. http://dx.doi.org/10.4159/harvard.9780674062757

Žižek, S. (2012a). The Year of Dreaming Dangerously. Londres y Nueva York: Verso.

Žižek, S. (2012b). Less than Nothing. Hegel and the Shadow of Dialectical Materialism. Londres y Nueva York: Verso. 